\title{
La France championne européenne de l'asile
}

\begin{abstract}
Patrie des droits de l'homme, la France s'interroge en permanence pour savoir si elle respecte cet héritage. Une composante des flux d'immigration, les demandes d'asile dans l'Union européenne, donne un éclairage à cette question : la France reste, parmi les 27 pays membres, celui qui reçoit le plus de demandes d'asile.
\end{abstract}

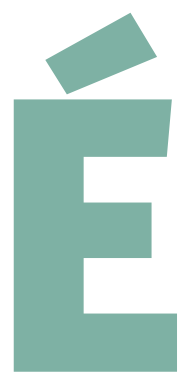

\section{La (triste) carte des difficultés géopolitiques du monde}

tudier la géographie des demandeurs d'asile ${ }^{1}$ présente d'abord un grand intérêt car elle dessine la (triste) carte des difficultés géopolitiques du monde dont la typologie suivante peut être mise en évidence :

- Pays connaissant ou ayant connu une situation de guerre impliquant d'autres pays : Afghanistan, Irak,

- Pays où des minorités souffrent de répression : Russie, Par Serbie $^{2}$, Turquie, Bangladesh,

- Pays en situation de guerre ou de conflit civils au moins sur une partie du territoire : Somalie, Sri Lanka, Congo RDC,

- Pays ayant, récemment ou non, acquis leur indépendance et connaissant divers facteurs d'instabilité : Kosovo, Macédoine, Pakistan ${ }^{3}$, Géorgie, Nigeria, Arménie, Guinée,

- Pays subissant un régime autoritaire pratiquant la répression : Iran, Chine, Syrie, Érythrée, Algérie.

Ainsi, les demandeurs d'asile qui déposent un dossier dans l'un des pays de l'Union européenne à 27 résultent moins de guerres internationales que de conflits géopolitiques internes. Le nombre de demandeurs d'asile dépend donc directement de l'évolution de la situation géopolitique des autres pays du monde. Le déclenchement ou l'accentuation d'une crise, comme les violences accrues au Sri Lanka en 2010, accentue ce nombre. En revanche, si des crises se résolvaient ou des pays aujourd'hui en difficulté progressaient vers un État de droit, le nombre de demandeurs d'asile pourrait diminuer.

\section{Une répartition inégale}

Dans la situation présente, il faut constater que les demandeurs d'asile se répartissent de façon inégale dans les pays de l'Union européenne. Ainsi, pour 2010, la France, reste le pays ayant reçu le plus de demandeurs d'asile ${ }^{4}$, devant l'Allemagne, la Suède, la Belgique et le RoyaumeUni. Cet ordre montre que les demandeurs d'asile ne se répartissent pas au prorata de la population des pays puisque la France est moins peuplée que l'Allemagne. En outre, parmi ces cinq pays européens comptant le plus de demandeurs d'asile, n'apparaissent pas le quatrième pays le plus peuplé de l'Union européenne, l'Italie, ni les cinq, six et septième, soit l’Espagne, la Pologne et la Roumanie.

1. LES PRINCIPAUX PAYS D'ORIGINE

DES DEMANDEURS D'ASILE

\section{DANS L'UNION EUROPÉENNE À 27}

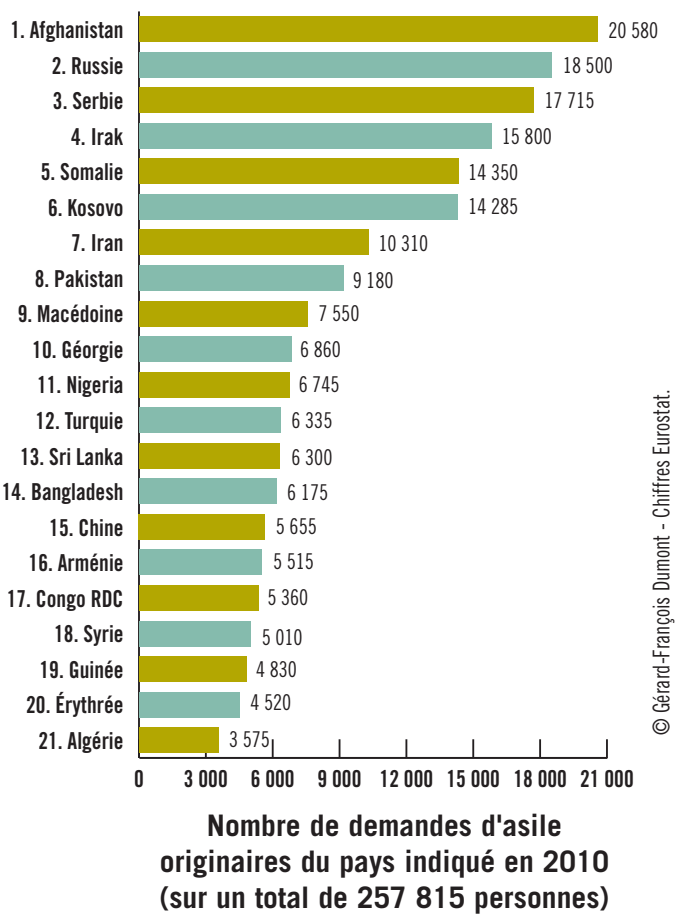


2. LES DEMANDEURS D'ASILE SELON LES PAYS DE L'UNION EUROPÉENNE À 27

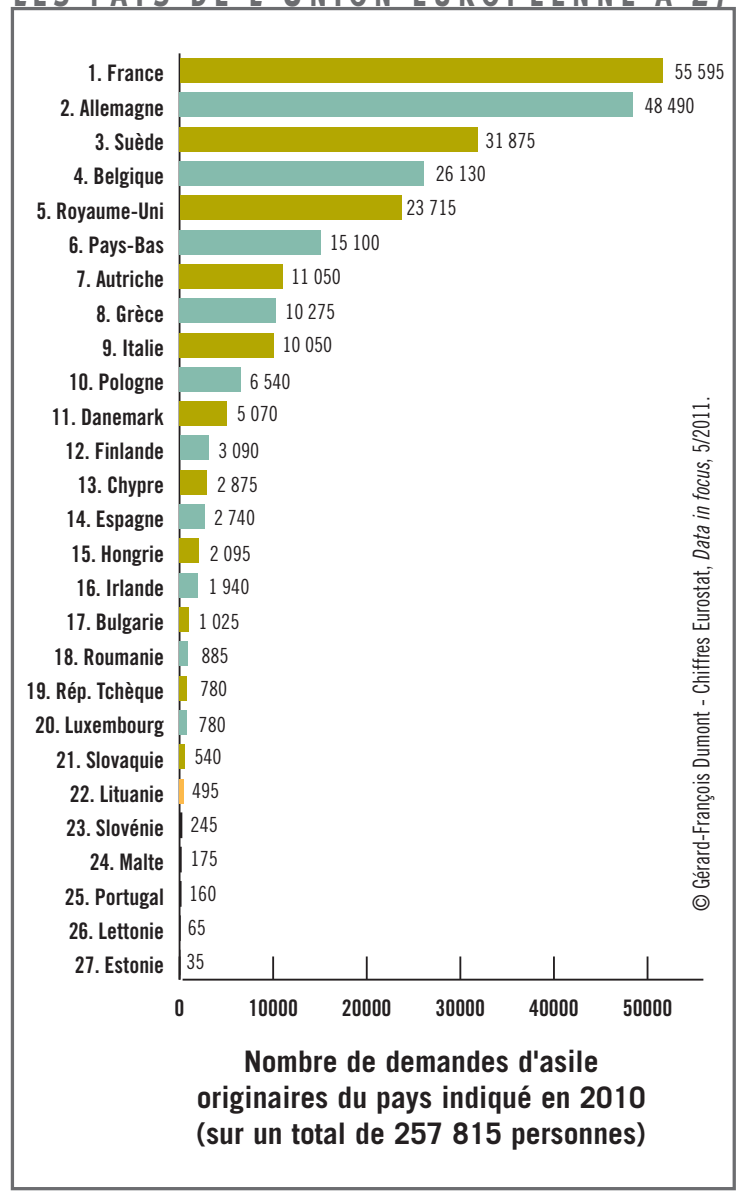

En revanche, des pays européens moins peuplés comptent un nombre de demandeurs d'asile proportionnellement élevé par rapport à leur population : il s'agit d'abord de la Suède qui s'est voulue particulièrement accueillante, notamment pour les Irakiens, souvent de confession chrétienne, et les Somaliens. La tradition de neutralité de ce pays concourt aussi à expliquer un taux de 3410 demandeurs d'asile par million d'habitants alors que la moyenne dans l'Union européenne est de 515. Concernant la Belgique (un taux de 2 410), faut-il penser que les demandeurs d'asile la voie comme la porte d'entrée de l'Union européenne en raison de la présence de la capitale communautaire, Bruxelles ? Pour les deux autres pays, dont la proportion des demandeurs d'asile rapportée à leur population est particulièrement élevée, Chypre (3 580) et l'Autriche $(1320)$, s'exerce une forte logique géographique. Chypre reçoit notamment des demandes d'asile de personnes originaires d'Irak et d'Égypte. Pour l'Autriche, sa proximité avec l'ex-Yougoslavie continue d'exercer des effets, tandis que son type de neutralité géopolitique demeure un élément significatif pour des demandeurs d'asile d'autres pays.

\section{La grande diversité des origines}

Dans la plupart des pays européens, les origines géographiques des demandeurs d'asile sont très diverses. Ne font exception que la Pologne où la Russie représente $73 \%$ des demandeurs d'asile et la Lituanie avec $50 \%$ des demandeurs d'asile d'origine géorgienne et $22 \%$ d'origine russe. Cette diversité se constate donc aussi en France où la première origine géographique des demandeurs d'asile, toujours pour l'année 2010, est le Kosovo, qui représente seulement $10 \%$ des personnes concernées. Suivent la Russie, le Bangladesh, le Congo RDC et le Sri Lanka.

Même si les demandes d'asile ne donnent pas toutes lieu à l'octroi du statut de réfugiés, elles mesurent bien l'une des composantes des flux d'immigration car seule une faible proportion des rejets de demandes d'asile se traduit par un retour au pays d'origine.

\section{LA RÉPARTITION}

\section{DES DEMANDES D'ASILE}

\section{SELON LES PAYS}

\section{DE L'UNION}

\section{EUROPÉENNE}

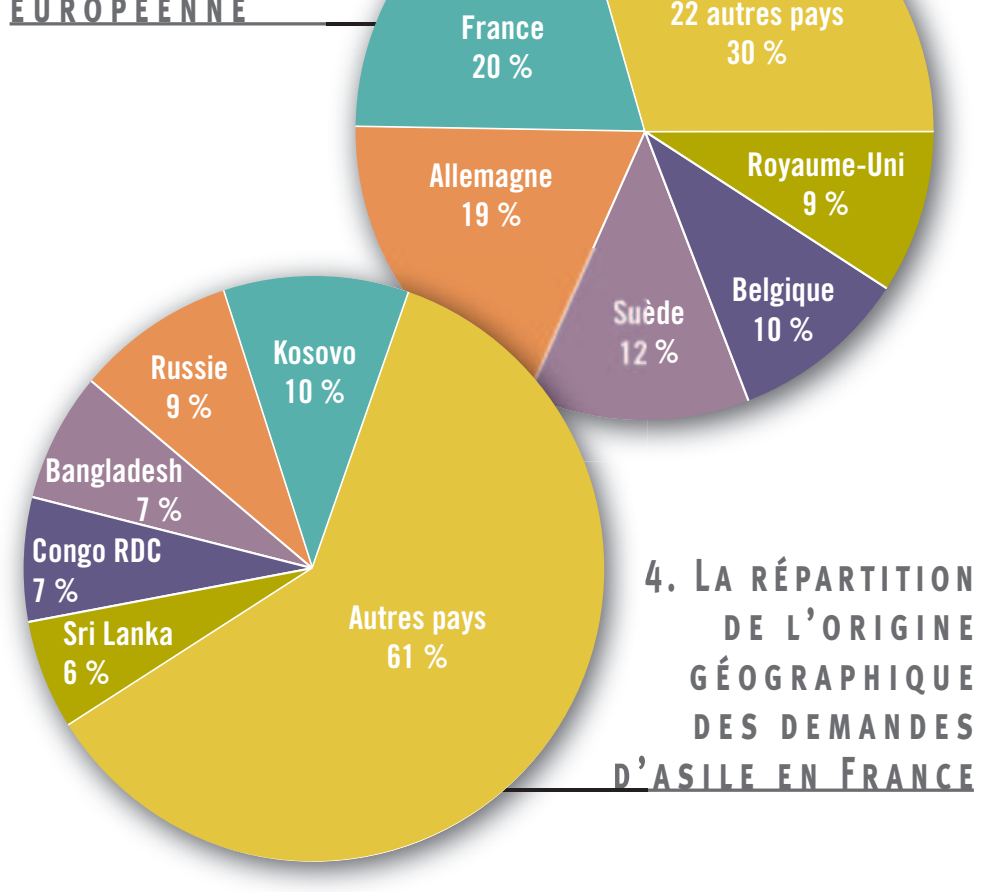

1. Un demandeur d'asile est une personne ayant déposé une demande de protection internationale ou qui a été incluse dans cette demande en tant que membre de la famille conformément à la Convention de Genève. ; cf. Dumont, GérardFrançois, Démographie politique. Les lois de la géopolitique des populations, Paris, Ellipses, 2007.
2. L'importance des demandes d'asiles 2010 déposées par des Serbes et par des Macédoniens semble s'expliquer par la levée de 'obligation de visa d'entrée dans 'Union européenne pour les ressortissants de ces deux pays depuis 2009.
3. Dumont, Gérard-Francois, Pakistan : un échec étatique ttesté par la démographie Outre-Terre, n² 24, 2010.

4. La France tient la 2e place dans le monde, légèrement derrière les États-Unis. 